\title{
¿Convergencia de la regulación contable colombiana para las entidades de gobierno con las International Public Sector Accounting Standards (IPSAS)? Una medición de la armonización formal
}

\section{Carlos Orlando Rico Bonilla, Michael Andrés Díaz Jiménez}

\author{
Universidad Santo Tomás - Facultad de Contaduría Pública
}

Colombia

En el documento, se desarrolla una medición de la armonización formal entre el marco normativo aplicable a las entidades de Gobierno en Colombia y las International Public Sector Accounting Standards (IPSAS). Para tal fin, se emplea la metodología de las distancias euclidianas, una herramienta estadística que consiste en comparar y asignar un parámetro numérico a las divergencias presentadas entre principios y tratamientos contables alternativos.

Se concluye que, a pesar de los avances en la estrategia de convergencia implementada por la Contaduría General de la Nación (CGN), la entidad emisora de las normas de contabilidad para el sector público en Colombia, aún hay diferencias desde el punto de vista normativo-técnico que pueden disminuir los beneficios potenciales de un proceso de paridad con estándares internacionales de general aceptación, en particular, la comparabilidad de la información financiera gubernamental.

Palabras clave: entidades de Gobierno, contabilidad gubernamental, IPSAS, armonización formal, convergencia contable, comparabilidad

\section{Convergence of the Colombian public-sector regulation accounting with the IPSAS? A measurement of formal harmonization}

The paper develops a measurement of formal harmonization between the regulatory Framework applicable to Government Entities and the International Public-Sector Accounting Standards (IPSAS). For this purpose, the methodology of Euclidean distances is used, a statistical tool that consists of comparing and assigning a numerical score to the divergences and coincidences presented between alternative accounting principles and treatments.

It's concluded that, despite of the advances in the convergence strategy implemented by the Contaduría General de la Nación (CGN), the entity standard-setting of public sector accounting in Colombia, there are still differences from the normative-technical point of view, which can diminish the potential benefits of a parity process with standards international of general acceptance, especially, the comparability of governmental financial information

Keywords: Governmental entities, governmental accounting, IPSAS, formal harmonization, accounting convergence, comparability 


\section{Convergência do Regulamento de Contabilidade da Colômbia para Entidades Governamentais com as International Public Sector Accounting Standards (IPSAS)? A Mediçáo da Harmonizaçáo Formal}

No documento desenvolve uma medida de harmonizaçáo formalentre o Quadro Normativo aplicável às Entidades Governamentais da Colômbia e as International Public Sector Accounting Standards (IPSAS). Para isso, é utilizada a metodologia de distâncias euclidianas, uma ferramenta estatística que consiste em comparar e atribuir um parâmetro numérico às divergências e coincidências apresentadas entre princípios e tratamentos de contabilidade alternativos.

Conclui-se que, apesar dos avanços na estratégia de convergência implementada pela Contaduría General de la Nación (CGN), a entidade que emite padróes contábeis para o setor público na Colômbia, ainda existem diferenças do ponto de vista normativo-técnico, o que pode diminuir os benefícios potenciais de um processo de paridade com padrôes internacionais de aceitação geral, em particular, a comparabilidade das informaçôes financeiras do governo.

Palavras-chave: Entidades governamentais, contabilidade do governo, IPSAS, Harmonização formal, convergência contábil, comparabilidade

\section{Introducción}

Cubrir las nuevas y diferentes necesidades de información financiera y no financiera que requieren los diferentes agentes sociales, en el marco de la globalización económica, demanda un proceso de adaptación, así como evaluación de los principios y reglas contables que se aplican en una nación determinada. En las últimas décadas, en el caso de Colombia y más extensamente de América Latina, se han realizado diferentes esfuerzos institucionales para converger hacia estándares internacionales de general aceptación (Caba y López, 2003; Caba y Caba, 2005; Brusca, Gómez y Montesinos, 2012; Brusca, Gómez y Montesinos, 2016).

Uno de los impactos técnicos que se espera de este proceso es la modificación de los conceptos y tratamientos contables sobre reconocimiento de los hechos económicos, diversos métodos de valoración, y revelaciones más amplias y exigentes en los reportes financieros. El objetivo es mejorar la transparencia, la calidad y la comparabilidad de dicha información tanto en la esfera privada como en la del sector público.

En este sentido, la convergencia de la regulación local con las IPSAS (International Public Sector Accounting
Standards) en el caso de las entidades de gobierno, adelantada recientemente por la Contaduría General de la Nación (CGN), se dirige a materializar una serie de beneficios potenciales. Entre ellos, se encuentran, ayudar a presentar cifras más fiables y completas sobre la situación y el desempeño financiero del sector público, mostrar una realidad económica más fidedigna y facilitar la administración de los recursos públicos (Bohórquez, 2016). De la misma forma, se busca garantizar una mayor calidad de la información financiera para el proceso de toma de decisiones y generar una mejor percepción de la economía en el entorno internacional (Bohórquez, 2016).

Para analizar y entender estos cambios en la normatividad local de la contabilidad del sector público, especialmente, en el caso de las entidades de gobierno, es necesario investigar la naturaleza, el significado y el alcance de los mismos. Frente a ello, en este documento, utilizando la metodología de las distancias euclidianas, se desarrolla una medición de la armonización formal entre el marco normativo aplicable a las mencionadas entidades y las IPSAS. De este modo, se busca contribuir con el estudio empírico del tema. 
El trabajo se divide en cuatro partes. En la primera, se realiza una revisión y una síntesis del modelo contable implementado por la CGN, y se enuncian los tres esquemas normativos contables que tienen vigencia a la fecha para el sector público colombiano en general. En el segundo apartado, se expone la literatura de investigación referente a la medición de la armonización contable. Se enfatiza la división entre armonización material y formal reseñando cómo este trabajo se circunscribe en esta última clase de análisis de la regulación contable.

En las partes tres y cuatro, se describe y emplea la metodología de las distancias euclidianas en la comparación de las normas locales colombianas del sector público, aplicables a las entidades de gobierno con las IPSAS. De igual forma, se presenta el alcance y los resultados más relevantes del estudio. Finalmente, se formulan las conclusiones y las perspectivas de investigación futuras.

\section{Estrategia de convergencia contable del sector público colombiano}

El proceso de convergencia hacia modelos internacionales ha requerido cambios sustanciales en el sistema de regulación contable colombiano. Desde la expedición de la ley 1314 de 2009, se reafirmaron facultades legales a la CGN para el ámbito del sector público; y al Ministerio de Hacienda y Crédito Público (MHCP), y al Ministerio de Comercio, Industria y Turismo (MCIT) en el caso del sector privado. Estos organismos son los que pueden expedir principios, normas, interpretaciones, y guías de contabilidad con el fin de lograr y mantener la calidad de la información financiera.

En este sentido, la CGN, en el marco de su misión constitucional y con el objetivo de lograr la modernización del régimen de contabilidad pública colombiano, presentó en 2013 el proyecto de «Estrategia de convergencia de la regulación contable pública hacia
Normas Internacionales de Información Financiera NIIF y Normas Internacionales de Contabilidad para el Sector Público NICSP» (Bohórquez, 2016). Este documento se convirtió en el punto de partida para la emisión de un compendio de pronunciamientos y declaraciones normativas que han significado la orientación y directriz para converger con un enfoque contable internacional. Tal estrategia plantea la política de regulación contable pública como la definición de tres marcos normativos (CGN, 2013):

- Un esquema de contabilidad para empresas públicas emisoras de valores, o que captan o administran ahorro del público

- Otro dirigido a empresas públicas no emisoras de valores, o que no captan ni administran ahorro del público

- Un marco normativo contable para entidades de gobierno

El primer modelo se implementó mediante la resolución 743 de 2013 de la CGN y sus complementos, que incluían agregar como parte de la regulación contable del sector público el Decreto 2784 de 2012 de Ejecutivo nacional, parámetro normativo por el que se converge con las International Financial Reporting Standards (IFRS) plenas en algunas corporaciones privadas colombianas.

Esta reglamentación es aplicable, entre otras, a aquellas empresas públicas que sean emisoras de valores, sociedades fiduciarias, establecimientos bancarios, entidades aseguradoras, fondos de garantías, entidades financieras con regímenes especiales y al Banco de la República de Colombia. El período establecido para desarrollar el proceso de implementación fue el comprendido entre el 1 de enero de 2014 y el 31 de diciembre de 2016. Durante este plazo, se establecieron tres fases: preparación obligatoria, transición, y de aplicación y reporte.

Contabilidad y Negocios (12) 24, 2017 / ISSN 1992-1896 
Para el segundo caso, el de las empresas públicas no emisoras de valores, o que no captan ni administran ahorro del público, la CGN emitió la resolución 414 de 2014, que establece un marco conceptual; normas para el reconocimiento, medición, revelación y presentación de los hechos económicos; un nuevo catálogo de cuentas; y guías e instructivos de implementación complementarios. El plazo para su apropiación va desde septiembre de 2014 al 31 de diciembre de 2017, con las mismas tres fases mencionadas en el caso anterior. Sin embargo, cabe anotar que, para las entidades que conforman el Sistema General de Seguridad Social en Salud (SGSSS), se ampliaron los tiempos.

De similar manera, para el tercer caso, el de las entidades de gobierno, la CGN presentó la resolución 533 de 2015. Con esta, se plantea el marco conceptual para la preparación y presentación de la información financiera; las normas para el reconocimiento, medición, revelación y presentación de los hechos económicos en entidades de gobierno; y un nuevo catálogo de cuentas. Estos se encuentran acompańados de procedimientos e instructivos para su implementación, en convergencia — como se mencionó antes- con las IPSAS.

A diferencia de los grupos anteriores, en este caso, no se consideró inicialmente un período de transición, solamente una fase de preparación obligatoria y una fecha de aplicación efectiva, la cual se esperaba fuera el 1 de enero de 2017. Posteriormente, a finales de 2016, la CGN emitió la resolución 693, que modificó el cronograma y amplió dos años la implementación de la nueva normatividad, que se espera que entre en marcha definitiva el 31 de diciembre de 2018.

En la tabla 1 se muestra un resumen de los principales pronunciamientos emitidos por la CGN a fin de complementar y fortalecer los referidos marcos normativos. Es importante resaltar que contar con tres esquemas diferentes, de por sí, genera poca armonización de la información contable del sector público. Esto puede incidir en una disminución de los beneficios potenciales de este proceso, en particular, cuando se trata de la razonabilidad y de la calidad de datos y cifras consolidadas.

Tabla 1. Marco normativo contable para las entidades del sector público en Colombia

\begin{tabular}{|c|c|c|c|c|c|}
\hline \multicolumn{2}{|c|}{$\begin{array}{l}\text { Marco normativo para las empresas del sector } \\
\text { público que cotizan en el mercado de valores, o que } \\
\text { captan o administran ahorro público }\end{array}$} & \multicolumn{2}{|c|}{$\begin{array}{c}\text { Marco normativo para empresas que no } \\
\text { cotizan en el mercado de valores, y que } \\
\text { no captan ni administran ahorro del } \\
\text { público }\end{array}$} & \multicolumn{2}{|c|}{$\begin{array}{c}\text { Marco normativo para entidades } \\
\text { de gobierno }\end{array}$} \\
\hline $\begin{array}{l}\text { Resolución } \\
743 \text { de } \\
2013\end{array}$ & $\begin{array}{l}\text { Incorpora en el régimen de conta- } \\
\text { bilidad pública el marco normativo } \\
\text { dispuesto en el anexo del decreto } \\
\text { nacional } 2784 \text { de } 2012 \text { (modificado } \\
\text { por el decreto } 2615 \text { de } 2014 \text { ) aplicable } \\
\text { a las entidades definidas en el artículo } \\
\text { segundo de dicha resolución. }\end{array}$ & $\begin{array}{l}\text { Resolución } \\
414 \text { de } \\
2014\end{array}$ & $\begin{array}{l}\text { Incorpora en el régimen } \\
\text { de contabilidad pública el } \\
\text { marco normativo aplicable } \\
\text { para empresas que no coti- } \\
\text { zan en el mercado de valores, } \\
\text { y que no captan ni adminis- } \\
\text { tran ahorro del público. }\end{array}$ & $\begin{array}{l}\text { Resolución } \\
533 \text { de } \\
2015\end{array}$ & $\begin{array}{l}\text { Incorpora en el régi- } \\
\text { men de contabilidad } \\
\text { pública el marco nor- } \\
\text { mativo aplicable para } \\
\text { entidades de gobierno. }\end{array}$ \\
\hline $\begin{array}{l}\text { Resolución } \\
598 \text { de } \\
2014\end{array}$ & $\begin{array}{l}\text { Modifica el artículo } 2 \text { de la resolución } \\
743 \text { de } 2013 \text { respecto al ámbito de } \\
\text { aplicación. }\end{array}$ & $\begin{array}{l}\text { Instructivo } \\
002 \text { de } \\
2014\end{array}$ & $\begin{array}{l}\text { Presenta las instrucciones } \\
\text { para la transición al marco } \\
\text { normativo para empre- } \\
\text { sas que no cotizan en el } \\
\text { mercado de valores, y que } \\
\text { no captan ni administran } \\
\text { ahorro del público. }\end{array}$ & $\begin{array}{l}\text { Instructivo } \\
002 \text { de } \\
2015:\end{array}$ & $\begin{array}{l}\text { Presenta las instruccio- } \\
\text { nes para la transición } \\
\text { al marco normativo } \\
\text { para entidades de } \\
\text { gobierno. }\end{array}$ \\
\hline
\end{tabular}




\begin{tabular}{|c|c|c|c|c|c|}
\hline \multicolumn{2}{|c|}{$\begin{array}{l}\text { Marco normativo para las empresas del sector } \\
\text { público que cotizan en el mercado de valores, o que } \\
\text { captan o administran ahorro público }\end{array}$} & \multicolumn{2}{|c|}{$\begin{array}{l}\text { Marco normativo para empresas que no } \\
\text { cotizan en el mercado de valores, y que } \\
\text { no captan ni administran ahorro del } \\
\text { público }\end{array}$} & \multicolumn{2}{|c|}{$\begin{array}{c}\text { Marco normativo para entidades } \\
\text { de gobierno }\end{array}$} \\
\hline $\begin{array}{l}\text { Resolución } \\
117 \text { de } \\
2015\end{array}$ & $\begin{array}{l}\text { Incorpora, como parte del régimen } \\
\text { de contabilidad pública, el marco } \\
\text { normativo para empresas que cotizan } \\
\text { en el mercado de valores o que captan } \\
\text { o administran ahorro del público, y } \\
\text { se define la estructura del catálogo } \\
\text { general de cuentas que se utilizará para } \\
\text { el reporte de información financiera de } \\
\text { las entidades obligadas a observar dicho } \\
\text { marco. }\end{array}$ & $\begin{array}{l}\text { Resolución } \\
139 \text { de } \\
2015\end{array}$ & $\begin{array}{l}\text { Incorpora, como parte del } \\
\text { régimen de contabilidad } \\
\text { pública, el marco norma- } \\
\text { tivo para empresas que no } \\
\text { cotizan en el mercado de } \\
\text { valores y que no captan } \\
\text { ni administran ahorro del } \\
\text { público, y se define la estruc- } \\
\text { tura del catálogo general de } \\
\text { cuentas que se utilizará para } \\
\text { el reporte de información } \\
\text { financiera de las entidades } \\
\text { obligadas a observar dicho } \\
\text { marco. }\end{array}$ & $\begin{array}{l}\text { Resolución } \\
620 \text { de } \\
2015\end{array}$ & $\begin{array}{l}\text { Incorpora el catálogo } \\
\text { general de cuentas al } \\
\text { marco normativo para } \\
\text { entidades de gobierno. }\end{array}$ \\
\hline $\begin{array}{l}\text { Resolución } \\
509 \text { de } \\
2015\end{array}$ & $\begin{array}{l}\text { Adiciona un parágrafo transitorio al } \\
\text { artículo } 2 \text { de la resolución } 743 \text { de } 2013 \\
\text { respecto a la aplicación de la contabili- } \\
\text { dad de coberturas en la presentación de } \\
\text { los primeros estados financieros. }\end{array}$ & $\begin{array}{l}\text { Resolución } \\
663 \text { de } \\
2015\end{array}$ & $\begin{array}{l}\text { Modifica el cronograma de } \\
\text { aplicación para las empresas } \\
\text { que conforman el Sistema } \\
\text { General de Seguridad Social } \\
\text { en Salud (SGSSS). }\end{array}$ & $\begin{array}{l}\text { Resolución } \\
113 \text { de } \\
2015\end{array}$ & $\begin{array}{l}\text { Incorpora la norma } \\
\text { de impuesto a las } \\
\text { ganancias, y modifica } \\
\text { la norma de acuerdos } \\
\text { de concesión desde } \\
\text { la perspectiva de la } \\
\text { entidad concedente } \\
\text { en las normas para } \\
\text { el reconocimiento, } \\
\text { medición, revelación } \\
\text { y presentación de los } \\
\text { hechos económicos del } \\
\text { marco normativo para } \\
\text { entidades de gobierno. }\end{array}$ \\
\hline $\begin{array}{l}\text { Resolución } \\
576 \text { de } \\
2015\end{array}$ & $\begin{array}{l}\text { Modifica el marco técnico normativo } \\
\text { para las empresas sujetas al ámbito } \\
\text { de la resolución } 743 \text { de } 2013 \text {, el cual } \\
\text { quedará tal y como se describe textual- } \\
\text { mente en el anexo del Decreto } 2615 \text { de } \\
2014 \text { y sus modificaciones. }\end{array}$ & $\begin{array}{l}\text { Resolución } \\
466 \text { de } \\
2016\end{array}$ & $\begin{array}{l}\text { Modifica el catálogo general } \\
\text { de cuentas del marco nor- } \\
\text { mativo para empresas que } \\
\text { no cotizan en el mercado } \\
\text { de valores, y que no captan } \\
\text { ni administran ahorro del } \\
\text { público. }\end{array}$ & $\begin{array}{l}\text { Resolución } \\
468 \text { de } \\
2016\end{array}$ & $\begin{array}{l}\text { Modifica el catálogo } \\
\text { general de cuentas del } \\
\text { marco normativo para } \\
\text { entidades de gobierno. }\end{array}$ \\
\hline $\begin{array}{l}\text { Resolución } \\
662 \text { de } \\
2015\end{array}$ & $\begin{array}{l}\text { Modifica el artículo } 2 \text { de la resolución } \\
743 \text { de } 2013 \text { respecto al ámbito de } \\
\text { aplicación. }\end{array}$ & & & $\begin{array}{l}\text { Resolución } \\
693 \text { de } \\
2016\end{array}$ & $\begin{array}{l}\text { Modifica el crono- } \\
\text { grama de aplicación } \\
\text { del marco normativo } \\
\text { para entidades de } \\
\text { gobierno. }\end{array}$ \\
\hline $\begin{array}{l}\text { Resolución } \\
467 \text { de } \\
2016\end{array}$ & $\begin{array}{l}\text { Modifica la estructura del catálogo } \\
\text { general de cuentas para las empresas } \\
\text { del sector público que cotizan en el } \\
\text { mercado de valores, o que captan o } \\
\text { administran ahorro público. }\end{array}$ & & & & \\
\hline
\end{tabular}

Fuente: CGN (2013, 2015a). Elaboración propia. 
Frente a ello, en la presente investigación, se examinará el grado de armonización formal entre las normas para el reconocimiento medición, revelación y presentación de los hechos económicos para entidades de gobierno de $2015^{1}$ (CGN, 2015b), y las IPSAS en el marco de la literatura de investigación contable descrita en el siguiente apartado.

\section{Literatura e investigación sobre medición de la armonización contable}

En el contexto de la literatura en la que se sustenta esta investigación, la armonización contable se entiende como un proceso en el que uno o varios agentes económicos — generalmente, emisores de estándares- buscan disminuir la cantidad de diferencias sobre al menos dos conjuntos de principios (reglas y métodos contables) en lo que respecta al reconocimiento, la medición, la presentación y la revelación de la información financiera (Rahman, Perera y Ganeshanandam, 1996; Garrido, León y Zorio, 2002; Caba y López, 2003; Caba y Caba, 2005; Fontes, Rodrigues y Craig, 2005; Fuertes, 2006, 2007).

La armonización de la práctica contable se puede desarrollar desde el interior de una corporación empresarial multinacional y sus sucursales o un gobierno, hasta un contexto global, como ha sido el sentido de la adopción en varias jurisdicciones de los estándares internacionales emitidos por el International Accounting Standards Board (IASB) para el sector privado, y el International Public Sector Accounting Standards Board (IPSASB), para el caso del sector público.

Este proceso se puede incluir o ser un complemento de otro referenciado en la literatura: la estandarización, cuyo fin más puntual es la reducción del número de principios, reglas y métodos alternativos disponibles en uno o varios cuerpos normativos. El objetivo es lograr una mayor uniformidad de las políticas y las cifras contables (Tay y Parker, 1990; McLeay, Neal y Tollington, 1999; González, 2006). Por ejemplo, en una jurisdicción en la que se adelanta una estrategia de armonización con la regulación internacional, pueden adoptarse las mismas fórmulas de cálculo de costo de inventarios (identificación específica, PEPS, promedio ponderado, etc.). Por su parte, en un ejercicio de estandarización, la idea sería más bien reducir estos tratamientos alternativos restringiendo su aplicación.

Un mayor grado de armonización o estandarización genera una restricción sobre el número de tratamientos aplicables, y, por ende, facilita el aumento de la comparabilidad, una característica cualitativa muy importante de la información financiera de calidad. Igualmente, influye en la rebaja de los costos de elaboración, análisis y auditoría de los datos y procesos contables, beneficio que pueden capitalizar múltiples usuarios (Van der Tas, 1988).

En la literatura consultada, se identifican dos dimensiones de la armonización contable: la formal (de jure) y la material (de facto). La primera corresponde a una menor diferenciación de los marcos regulatorios en sí mismos; es decir, se trata de equiparar los estándares, las guías y los procedimientos que sustentan tratamientos contables particulares. La segunda se refiere a la limitación o la eliminación de las discrepancias en el contexto de la práctica, es decir, en la aplicación concreta de un determinado lineamiento contable (Van der Tas, 1988; González, 2006; Fuertes, 2007).

1 Dichas normas se dividen en cinco capítulos: activos, pasivos, activos y pasivos contingentes, ingresos, otras normas, y presentación de estados financieros y revelaciones. 
El ejemplo sobre fórmulas de cálculo de costo de inventarios, descrito anteriormente, consiste en un caso de armonización formal. Es posible que, en el desarrollo práctico al interior de una organización, país o un conjunto de estos, se encuentre que la elección del tratamiento contable que sigue la mayoría de agentes económicos se reduce al uso de una o dos fórmulas establecidas, a pesar de tener varias alternativas en el estándar; esto es lo que se denomina armonización material. Este concepto es en el que se ha hecho mayor énfasis dentro de la literatura académica internacional.

Esto quiere decir que se puede tener una regulación similar entre diferentes países, lo que generaría los notables beneficios seńalados antes, pero esto no garantiza necesariamente su aplicación efectiva a la hora de elaborar y revelar información financiera cuando hay diferentes métodos alternativos. Por esta razón, si bien es relevante la infraestructura de endorsement o cadena de valor de los estándares contables en cada jurisdicción legal, cobran cada vez más importancia los temas de enforcement o cumplimiento forzoso de los mismos (Cavanagh y Fernández, 2015). El principal problema que surge es cómo medir, y gestionar los grados de armonización formal y material en un contexto de ejes económicos regionales e integración global cada vez más estructurados.

En esta medida, el establecimiento de indicadores y métricas matemáticas y estadísticas — por ejemplo, las distancias euclidianas - ayuda a definir de una manera concreta elementos de los estándares en los que hay mayores discrepancias. Asimismo, permite identificar de un modo empírico los incentivos y las restricciones asociados a la elección y al uso que se hace de determinados tratamientos contables. Además, hace posible evaluar de una forma esquemática el impacto de los cambios en la regulación a fin de lograr una convergencia significativa de las prácticas

organizacionales de reporte financiero (Van der Tas, 1988; Giner y Mora, 2001).

Las investigaciones y el análisis sobre este tema surgieron en el ámbito del proyecto de integración de la Unión Europea en la década de 1980, a partir de la necesidad de implementar las directivas IV y VII de 1983 de la Comunidad Europea. Vuelven a aparecer posteriormente, en 1999, con la estrategia de incorporación de las IFRS en la regulación de las cuentas de empresas cotizadas en Bolsas de Valores (Emenyonu y Gray, 1992; García, 1995; Herrmann y Thomas, 1995; Cañibano y Mora, 2000; Giner y Mora, 2001).

La literatura existente sobre el tema ha desarrollado un número amplio de metodologías para medir los procesos de armonización formal y material. A continuación, se presentan algunas de estas propuestas. Una de ellas es el índice H. Este indicador, desarrollado por Van der Tas (1988), sirve para determinar la concentración de un conjunto de entidades, respecto de la frecuencia en la aplicación de un tratamiento contable particular. Por ejemplo, en la medida en que una mayor proporción de empresas se incline por una práctica contable determinada, se podrá afirmar que aumentará la paridad de facto (Tay y Parker, 1990; González, 2006).

Otro indicador es el índice de comparabilidad o índice C. Este consiste en la proporción entre el número de coincidencias que se producen en la aplicación de un tratamiento contable entre diferentes entidades en relación con el conjunto de posibles coincidencias del universo que las mismas componen. Esto se puede ilustrar en el siguiente caso expuesto por Van der Tas: «[...] hay tres compañías (A, B y C) el número total de comparaciones es tres, esto es entre $\mathrm{A}$ y $\mathrm{B}, \mathrm{A}$ y $\mathrm{C}$ y entre B y C. Supongamos que la compañía A aplica el método contable I y las otras dos compañías aplican 
el método II. En este caso el grado de es 1/3, es decir, el número de pares coincidentes (uno, entre $\mathrm{B}$ y $\mathrm{C}$ ), dividido por el número total de comparaciones (tres)» (1988, p. 164 [traducción propia]). En este modelo, un aumento de las coincidencias en la elección contable de los agentes económicos implica un mayor grado de armonización, que impacta positivamente en la comparabilidad de la información financiera.

Así mismo, Morris y Parker (1998) realizan una completa evaluación de estos y otros indicadores de armonización material, y caracterizan sus propiedades, base de datos, limitaciones e inconvenientes técnicos. En las propuestas de Archer, Delvaille y McLeay (1995), y Krisement (1997), se plantean aplicaciones y desarrollos más amplios del índice de comparabilidad, mientras que, en las investigaciones de Archer, Delvaille y McLeay (1996), y McLeay y otros (1999), se diseñan modelaciones estadísticas que resultan en mediciones más amplias y estructuradas.

En cuanto a la armonización formal, buena parte de la literatura está concentrada en los análisis taxativos sobre los sistemas contables de diferentes países que, de acuerdo con su tradición legal y cultural común, aplican estándares o normas de contabilidad relativamente similares (Rahman y otros, 1996). Los más generales se circunscriben al entorno institucional de los esquemas contables anglosajones y su contraste con los continental-europeos (Jarne, 1997; Gómez y Montesinos, 2012).

Otra porción importante de las investigaciones se ha enfocado en el análisis de diversos marcos normativos evaluando el impacto de los cambios en los principios y en las reglas contables en los mercados de valores, los incentivos de los agentes económicos, la percepción y el análisis de la información financiera por parte de sus usuarios, entre otros aspectos (Rahman y otros,
1996). En estos estudios se utilizan diferentes tipos de fuentes: bases de datos, entrevistas, encuestas, reportes anuales, e incluso técnicas experimentales. Igualmente, se aplican diversas metodologías: desde los trabajos documentales o de análisis de derecho comparado de corte narrativo, hasta los modelos matemáticos, estadísticos y econométricos de perfil más empírico.

Precisamente, bajo estas últimas metodologías, se plantean investigaciones y propuestas que buscan medir la estandarización formal en términos de las distancias euclidianas, una herramienta estadística que consiste en comparar y asignar un parámetro numérico a las diferencias y coincidencias presentadas a fin de establecer los elementos conceptuales y técnicos en los que hay mayor diferenciación entre dos o más marcos normativos (Garrido y otros, 2002; Fontes y otros, 2005; Fuertes, 2007).

Rahman y otros (1996) elaboraron una comparación entre las regulaciones contables de Australia y Nueva Zelanda, en la que mostraron que, a pesar de proceder de una misma tradición y modelo contable de tipo anglosajón, se exteriorizaban divergencias considerables en algunos aspectos de la regulación, como las ganancias por acción, las pensiones y las propiedades de inversión.

Por su parte, Garrido y otros (2002) utilizaron esta metodología para evaluar el avance en la armonización de los estándares emitidos por el IASC - hoy IASB - desde su fundación en 1973 hasta la firma del acuerdo de entendimiento con el International Organization of Securities Commissions (IOSCO) en 1995. Concluyeron que, en principio, la normatividad contable internacional se caracterizaba por su alta diversidad y flexibilidad en cuanto al número de tratamientos contables alternativos permitidos y muestran cómo esta tendencia ha ido disminuyendo, 
especialmente, desde la adopción del marco conceptual, emitido en 1989.

Para el caso portugués, Fontes y otros (2005) analizaron la evolución de la armonización formal entre la legislación contable portuguesa y los IFRS en diferentes intervalos de tiempo entre 1973 y 2003. Su estudio evidencia un aumento de la similitud de las reglas y principios de contabilidad portugueses a partir de 1991 en detrimento de la influencia francesa que caracterizaba el sistema de regulación y las instituciones contables lusitanas.

Fuertes (2006, 2007) evalúo el modelo contable público de las IPSAS, en términos de la amplitud de tratamientos contables alternativos permitidos. Concluyó que el mismo es de orientación normalizadora, con bastante limitación de la discrecionalidad a la elección de opciones de política contable.

Tomando como referencia estas perspectivas de la literatura, y considerando la relevancia del actual proceso de convergencia que adelantan las entidades de gobierno en Colombia al implementar la resolución 533 de 2015 expedida por la CGN, es pertinente evaluar la armonización formal con respecto a las IPSAS. En seguida, se describe el proceso elaborado para tal fin.

\section{Procedimiento metodológico}

En primer lugar, se ha identificado de forma concreta el conjunto de estándares que serán objeto de comparación. En este caso, se trata de las IPSAS de base de devengo vigentes al cierre del año 2015 (34 en total). No se contemplan las cuatro ya derogadas (números 6, 7, 8 y 15), el estándar de base contable de caja ni las tres guías de práctica recomendadas por el IPSASB. En la tabla 2 se muestran el listado de estos pronunciamientos con su respectiva equivalencia en las normas colombianas para entidades de gobierno, emitidas por la CGN.

Como se puede apreciar, hay una importante fuente de disparidad que surge entre los dos cuerpos normativos: se trata de las IPSAS número 10, 20, 22, 33, 34 y 38, que contienen - entre otros - temas como el tratamiento contable de la información financiera en contextos inflacionarios, y revelaciones sobre partes relacionadas y otras entidades. Tampoco, hay un pronunciamiento local que aborde el tema del reporte de presupuestos (número 24), un aspecto central en la toma de decisiones asociada a la gestión y la rendición de cuentas de las entidades de gobierno, en el que se generan dificultades al intentar compatibilizar un esquema de contabilidad financiera de devengo y un modelo de gestión presupuestaria de base de caja (Pereira y Correa, 2013; Cavanagh y Fernández, 2015; Aggestam-Pontoppidan y Andernack, 2016).

También, hay aspectos que están reglamentados localmente, pero no están contemplados en los estándares internacionales, como los bienes de uso público, recursos naturales no renovables y la administración de recursos de seguridad social en pensiones ${ }^{2}$. Todas estas temáticas, que indudablemente tienen una justificación de desarrollo local, influyen en la armonización formal, puesto que implican una distancia de los tratamientos contables correspondientes, con la cual disminuye la comparabilidad de los dos modelos normativos y la información financiera resultado de los mismos. Por esta razón, tampoco se contemplaron en el desarrollo del ejercicio empírico.

2 Como se reseña en la tabla 1, por medio de la resolución 113 de 2015 de la CGN, también se incorporaron reglas sobre impuesto a las ganancias que aumentarán la disparidad. 
Tabla 2. Listado de IPSAS y su equivalente en la regulación colombiana (2015)

\begin{tabular}{|c|c|c|c|c|}
\hline $\begin{array}{l}\text { No. } \\
\text { IPSAS }\end{array}$ & Nombre & Fecha de emisión & $\begin{array}{l}\text { No. } \\
\text { párrafos }\end{array}$ & $\begin{array}{l}\text { Norma colombiana para } \\
\text { entidades de gobierno }\end{array}$ \\
\hline 1 & Presentación de estados financieros & Mayo 2000 & 155 & Capítulo VI, numeral 1 \\
\hline 2 & Estado de flujos de efectivo & Mayo 2000 & 64 & Capítulo VI, numeral 1 \\
\hline 3 & $\begin{array}{l}\text { Políticas contables, cambios en las estimaciones contables y } \\
\text { errores }\end{array}$ & Mayo 2000 & 61 & Capítulo VI, numeral 4 \\
\hline 4 & $\begin{array}{l}\text { Efectos de las variaciones en las tasas de cambio de la moneda } \\
\text { extranjera }\end{array}$ & Mayo 2000 & 73 & Capítulo V, numeral 2 \\
\hline 5 & Costos por préstamos & Mayo 2000 & 43 & Capítulo I, numeral 18 \\
\hline 6 & Estados financieros consolidados y separados & Mayo 2000 & 71 & NIA (Derogada NICSP 35) \\
\hline 7 & Inversiones en asociadas & Mayo 2000 & 49 & NIA (Derogada NICSP 36) \\
\hline 8 & Participaciones en negocios conjuntos & Mayo 2000 & 71 & NIA (Derogada NICSP 37) \\
\hline 9 & Ingresos de transacciones con contraprestación & Julio 2001 & 42 & Capítulo IV, numeral 2 \\
\hline 10 & Información financiera en economías hiperinflacionarias & Julio 2001 & 39 & Sin equivalente \\
\hline 11 & Contratos de construcción & Julio 2001 & 58 & Capítulo IV, numeral 3 \\
\hline 12 & Inventarios & Julio 2001 & 53 & Capítulo I, numeral 9 \\
\hline 13 & Arrendamientos & Diciembre 2001 & 87 & Capítulo I, numeral 16 \\
\hline 14 & Hechos ocurridos después de la fecha de presentación & Diciembre 2001 & 34 & Capítulo VI, numeral 5 \\
\hline 15 & $\begin{array}{l}\text { Instrumentos financieros: presentación e información a } \\
\text { revelar }\end{array}$ & Diciembre 2001 & 104 & $\begin{array}{l}\text { N/A (Derogada NICSP 28, 29, } \\
\text { y 30) }\end{array}$ \\
\hline 16 & Propiedades de inversión & Diciembre 2001 & 103 & Capítulo I, numeral 14 \\
\hline 17 & Propiedades, planta y equipo & Diciembre 2001 & 109 & Capítulo I, numeral 10 \\
\hline 18 & Información financiera por segmentos & Junio 2002 & 77 & Capítulo VI, numeral 3 \\
\hline 19 & Provisiones, pasivos contingentes y activos contingentes & Octubre 2002 & 113 & $\begin{array}{l}\text { Capítulo II, numeral } 6 \text { y } \\
\text { Capítulo III }\end{array}$ \\
\hline 20 & Información a revelar sobre partes relacionadas & Octubre 2002 & 43 & Sin equivalente \\
\hline 21 & Deterioro del valor de activos no generadores de efectivo & Diciembre 2004 & 83 & Capítulo I, numeral 20 \\
\hline 22 & $\begin{array}{l}\text { Revelación de información financiera sobre el sector gobierno } \\
\text { general }\end{array}$ & Diciembre 2006 & 48 & Sin equivalente \\
\hline 23 & $\begin{array}{l}\text { Ingresos de transacciones sin contraprestación (impuestos y } \\
\text { transferencias) }\end{array}$ & Diciembre 2006 & 125 & Capítulo IV, numeral 1 \\
\hline 24 & $\begin{array}{l}\text { Presentación de información del presupuesto en los estados } \\
\text { financieros }\end{array}$ & Diciembre 2006 & 55 & Sin equivalente \\
\hline 25 & Beneficios a los empleados & Diciembre 2006 & 178 & Capítulo II, numeral 5 \\
\hline 26 & Deterioro del valor de activos generadores de efectivo & Febrero 2008 & 127 & Capítulo I, numeral 19 \\
\hline 27 & Agricultura & Diciembre 2009 & 57 & Capítulo I, numeral 17 \\
\hline 28 & Instrumentos financieros: Presentación & Enero 2010 & 62 & $\begin{array}{l}\text { Capítulo I, numerales } 1,2,3,4 \text { y } \\
\text { Capítulo II, numerales } 1,2,3,4\end{array}$ \\
\hline
\end{tabular}




\begin{tabular}{|c|l|l|c|l|}
\hline $\begin{array}{c}\text { No. } \\
\text { IPSAS }\end{array}$ & \multicolumn{1}{|c|}{ Nombre } & Fecha de emisión & $\begin{array}{c}\text { No. } \\
\text { párrafos }\end{array}$ & \multicolumn{1}{|c|}{$\begin{array}{c}\text { Norma colombiana para } \\
\text { entidades de gobierno }\end{array}$} \\
\hline 29 & Instrumentos financieros: Reconocimiento y medición & Enero 2010 & 126 & $\begin{array}{l}\text { Capítulo I, numerales 1, 2, 3, 4y } \\
\text { Capítulo II, numerales 1,2,3, 4 }\end{array}$ \\
\hline 30 & Instrumentos financieros: Información a revelar & Enero 2010 & 54 & $\begin{array}{l}\text { Capítulo I, numerales 1, 2, 3, 4 y } \\
\text { Capítulo II, numerales 1, 2, 3, 4 }\end{array}$ \\
\hline 31 & Activos intangibles & Enero 2010 & 133 & Capítulo I, numeral 15 \\
\hline 32 & Acuerdos de concesión de servicios: La concedente & Octubre 2011 & 37 & Capítulo V, numeral 1 \\
\hline 33 & $\begin{array}{l}\text { Adopción por primera vez de las normas internacionales de } \\
\text { contabilidad del sector de base de acumulación (devengo) }\end{array}$ & Enero 2015 & 154 & Sin equivalente \\
\hline 34 & Estados financieros separados & Enero 2015 & 34 & Sin equivalente \\
\hline 35 & Estados financieros consolidados & Enero 2015 & 81 & Capítulo VI, numeral 2 \\
\hline 36 & Inversiones en asociadas y negocios conjuntos & Enero 2015 & 53 & Capítulo I, numeral 6 y 7 \\
\hline 37 & Acuerdos conjuntos & Enero 2015 & 44 & Capítulo I, numeral 7 \\
\hline 38 & Información a revelar sobre participaciones en otras entidades & Enero 2015 & 62 & Sin equivalente \\
\hline
\end{tabular}

En segundo lugar, como sugiere la literatura sobre el tema, los conceptos y los tratamientos contables identificados en cada estándar internacional y en las respectivas normas colombianas se han clasificado en elementos de información y elementos de valoración. En los primeros, se incluyen los lineamientos sobre el reconocimiento, la revelación y la presentación de información financiera, es decir, cuando se debe captar la información en el proceso contable y su divulgación. Los segundos indican directrices respecto a la medición de los elementos de los estados financieros.

Por ejemplo, en la IPSAS 27 párrafo número 13, se mencionan los parámetros que se deben tener en cuenta para reconocer un activo biológico o producto agrícola en la contabilidad (que la entidad controle el activo como resultado de sucesos pasados, sea probable que la entidad reciba beneficios económicos futuros o potencial de servicio relacionado al bien y fiabilidad de la medición) (IPSASB, 2015, p. 1001). Este sería un tratamiento contable de información. En este mismo estándar, en el párrafo número 16 , se dispone que un activo biológico se medirá en el momento inicial y en cada fecha de presentación por su valor razonable menos los costos de venta, salvo este no pueda ser medido con fiabilidad (IPSASB, 2015, p. 1001). Esto es un tratamiento contable de valoración.

En la tabla 3 se presentan la información de las IPSAS analizadas y su equivalencia local, indicando el número total de conceptos y tratamientos contables identificados, y la discriminación de los mismos de acuerdo con las clases de información/valoración.

En el caso de las IPSAS, se han establecido un total de 482 conceptos y tratamientos contables. Para mantener la objetividad en su identificación, la búsqueda de los mismos se ha concentrado en los párrafos presentados en tipografía negrilla, que, acorde con el prólogo de estos pronunciamientos, indica los principios más relevantes (IPSASB, 2015). No se incluyen los lineamientos sobre objetivos, alcance, glosario, disposiciones transitorias y fecha de vigencia, debido a que generarían una diferenciación incorrecta. 
Tabla 3. Número de conceptos y tratamientos contables de información y valoración de las IPSAS y la normativa contable colombiana de entidades de gobierno (2015)

\begin{tabular}{|c|c|c|c|c|c|c|c|}
\hline \multirow[b]{2}{*}{$\begin{array}{l}\text { No. } \\
\text { IPSAS }\end{array}$} & \multirow[b]{2}{*}{ Tópico } & \multicolumn{3}{|c|}{ IPSAS } & \multicolumn{3}{|c|}{ Norma colombiana } \\
\hline & & $\begin{array}{c}\text { \# de conceptos } \\
\text { y tratamientos } \\
\text { contables } \\
\text { regulados }\end{array}$ & $\begin{array}{c}\text { \# de } \\
\text { ítems de } \\
\text { información }\end{array}$ & $\begin{array}{c}\text { \# de } \\
\text { ítems de } \\
\text { valoración }\end{array}$ & $\begin{array}{c}\text { \# de conceptos } \\
\text { y tratamientos } \\
\text { contables } \\
\text { regulados }\end{array}$ & $\begin{array}{c}\text { \# de } \\
\text { ítems de } \\
\text { información }\end{array}$ & $\begin{array}{c}\text { \# de } \\
\text { ítems de } \\
\text { valoración }\end{array}$ \\
\hline 1 & Presentación de estados financieros & 47 & 47 & 0 & 33 & 33 & 0 \\
\hline 2 & Estado de flujos de efectivo & 17 & 17 & 0 & 12 & 12 & 0 \\
\hline 3 & $\begin{array}{l}\text { Políticas contables, cambios en las } \\
\text { estimaciones contables y errores }\end{array}$ & 16 & 16 & 0 & 16 & 16 & 0 \\
\hline 4 & $\begin{array}{l}\text { Efectos de las variaciones en las tasas } \\
\text { de cambio de la moneda extranjera }\end{array}$ & 8 & 7 & 1 & 8 & 7 & 1 \\
\hline 5 & Costos por préstamos & 10 & 8 & 2 & 10 & 8 & 2 \\
\hline 9 & $\begin{array}{l}\text { Ingresos de transacciones con contra- } \\
\text { prestación }\end{array}$ & 12 & 10 & 2 & 11 & 10 & 1 \\
\hline 11 & Contratos de construcción & 9 & 7 & 2 & 6 & 4 & 2 \\
\hline 12 & Inventarios & 13 & 8 & 5 & 9 & 7 & 2 \\
\hline 13 & Arrendamientos & 23 & 18 & 5 & 18 & 16 & 2 \\
\hline 14 & $\begin{array}{l}\text { Hechos ocurridos después de la fecha } \\
\text { de presentación }\end{array}$ & 6 & 6 & 0 & 4 & 4 & 0 \\
\hline 16 & Propiedades de inversión & 13 & 6 & 7 & 8 & 4 & 4 \\
\hline 17 & Propiedades, planta y equipo & 17 & 8 & 9 & 15 & 7 & 8 \\
\hline 18 & Información financiera por segmentos & 12 & 12 & 0 & 5 & 5 & 0 \\
\hline 19 & $\begin{array}{l}\text { Provisiones, pasivos contingentes y } \\
\text { activos contingentes }\end{array}$ & 21 & 16 & 5 & 19 & 15 & 4 \\
\hline 21 & $\begin{array}{l}\text { Deterioro del valor de activos no } \\
\text { generadores de efectivo }\end{array}$ & 12 & 9 & 3 & 11 & 9 & 2 \\
\hline 23 & $\begin{array}{l}\text { Ingresos de transacciones sin contra- } \\
\text { prestación (impuestos y transf.) }\end{array}$ & 18 & 12 & 6 & 15 & 11 & 4 \\
\hline 25 & Beneficios a los empleados & 32 & 19 & 13 & 27 & 14 & 13 \\
\hline 26 & $\begin{array}{l}\text { Deterioro del valor de activos genera- } \\
\text { dores de efectivo }\end{array}$ & 31 & 21 & 10 & 27 & 19 & 8 \\
\hline 27 & Agricultura & 10 & 5 & 5 & 6 & 4 & 2 \\
\hline 28 & Instrumentos financieros: Presentación & 12 & 12 & 0 & 9 & 9 & 0 \\
\hline 29 & $\begin{array}{l}\text { Instrumentos financieros: Reconoci- } \\
\text { miento y medición }\end{array}$ & 40 & 21 & 19 & 27 & 18 & 9 \\
\hline 30 & $\begin{array}{l}\text { Instrumentos financieros: Información } \\
\text { a revelar }\end{array}$ & 11 & 11 & 0 & 6 & 6 & 0 \\
\hline 31 & Activos intangibles & 34 & 19 & 15 & 25 & 16 & 9 \\
\hline
\end{tabular}




\begin{tabular}{|c|c|c|c|c|c|c|c|}
\hline \multirow[b]{2}{*}{$\begin{array}{l}\text { No. } \\
\text { IPSAS }\end{array}$} & \multirow[b]{2}{*}{ Tópico } & \multicolumn{3}{|c|}{ IPSAS } & \multicolumn{3}{|c|}{ Norma colombiana } \\
\hline & & $\begin{array}{c}\text { \# de conceptos } \\
\text { y tratamientos } \\
\text { contables } \\
\text { regulados }\end{array}$ & $\begin{array}{c}\text { \# de } \\
\text { ítems de } \\
\text { información }\end{array}$ & $\begin{array}{c}\text { \# de } \\
\text { ítems de } \\
\text { valoración }\end{array}$ & $\begin{array}{c}\text { \# de conceptos } \\
\text { y tratamientos } \\
\text { contables } \\
\text { regulados }\end{array}$ & $\begin{array}{c}\text { \# de } \\
\text { ítems de } \\
\text { información }\end{array}$ & $\begin{array}{c}\text { \# de } \\
\text { ítems de } \\
\text { valoración }\end{array}$ \\
\hline 32 & $\begin{array}{l}\text { Acuerdos de concesión de servicios: } \\
\text { La concedente }\end{array}$ & 17 & 15 & 2 & 14 & 13 & 1 \\
\hline 35 & Estados financieros consolidados & 14 & 14 & 0 & 9 & 9 & 0 \\
\hline 36 & $\begin{array}{l}\text { Inversiones en asociadas y negocios } \\
\text { conjuntos }\end{array}$ & 14 & 13 & 1 & 9 & 9 & 0 \\
\hline \multirow[t]{2}{*}{37} & Acuerdos conjuntos & 13 & 13 & 0 & 11 & 11 & 0 \\
\hline & $\begin{array}{c}\text { TOTAL } \\
\%\end{array}$ & 482 & $\begin{array}{l}370 \\
77 \%\end{array}$ & $\begin{array}{l}112 \\
23 \%\end{array}$ & 370 & $\begin{array}{l}296 \\
80 \%\end{array}$ & $\begin{array}{c}72 \\
20 \%\end{array}$ \\
\hline
\end{tabular}

Este mismo ejercicio se aplica en las normas colombianas, lo cual es un tanto más complejo, puesto que estas no están numeradas, y no se marcan o distinguen de algún modo los principios básicos que referencian uno o varios tratamientos contables sobre determinado elemento de los estados financieros. Se establecen 370 conceptos y tratamientos contables, un número mucho menor en relación con las IPSAS.

Como se puede evidenciar, la distribución entre las directrices informativas y de valoración es muy similar en una relación de $80 \%-20 \%$ en promedio en los dos cuerpos normativos. Los tópicos comunes que tienen una mayor concentración de lineamientos sobre información son los de presentación de estados financieros, deterioro del valor de activos generadores de efectivo, y reconocimiento y medición de instrumentos financieros. Estos dos últimos igualmente son los que más parámetros contienen en términos de valoración.

Bajo los parámetros del esquema de regulación adoptado en Colombia, el $97 \%$ de los principios contables identificados tiene un carácter de obligatorio, prohibido $(2 \%)$ y se presentan mínimos requerimientos con tratamientos alternativos permitidos (1\%).
Esta estandarización facilita la comparabilidad de la información al reducir la discrecionalidad en la formulación de políticas contables. Mientras, en las IPSAS, la orientación es menos rígida y permite un mayor componente de flexibilidad, manifiesto en un nivel de $10 \%$ de directrices con nivel de exigencia de permitidos, e incluso un pequeño margen de recomendados (1\%).

Estos factores instrumentales son, de hecho, indicios de otra significativa divergencia entre los modelos normativos: los estándares internacionales están basados, en su mayoría, en principios y están orientados a la comunicación del reporte financiero gubernamental. Las declaraciones locales están sustentadas en reglas; su objetivo es orientar el proceso contable y la elaboración de los estados financieros. Son dos filosofías de regulación disímiles: en la primera, se busca la relevancia de la información (fondo), mientras que, en la segunda, el tema sigue siendo el cumplimiento de un procedimiento legal (forma).

Uno de los aspectos en los que más se distingue esta situación es en la definición de los usuarios de la información: mientras en el marco conceptual que sustenta 
a las IPSAS se define como usuarios principales del reporte financiero a los ciudadanos y sus representantes en la autoridad legislativa, a nivel local, no hay ninguna priorización o jerarquía de los mismos, lo cual afecta a todo el esquema de emisión y a la revelación de los reportes financieros gubernamentales.

En tercer lugar, siguiendo igualmente investigaciones previas, los datos se distribuyen en una de las siguientes categorías, según el grado de exigencia requerido por el concepto o el tratamiento contable.

- Obligatorio, lo que el estándar exige para todos los sujetos abarcados por la norma

- Recomendado o sugerido por la norma

- Permitido, no obligatorio o no prohibido

- Prohibido expresamente por la norma

De esta manera, si un lineamiento contable, ya sea de información o valoración, se encuentra en los dos marcos normativos y los dos coinciden en ser, por ejemplo, prohibidos, hay armonización entre los mismos. De lo contrario, tendríamos una divergencia que se mediría acorde con la función de las distancias euclidianas. Como se ha mencionado con anterioridad, esta se trata de una herramienta estadística que consiste en comparar y asignar un parámetro numérico a las divergencias presentadas entre principios y tratamientos contables alternativos, y cuya notación matemática es la siguiente:

$$
D_{A}^{B}=\sum_{k=1}^{H} d_{k, A}^{B}
$$

En esta fórmula, $d(X, Y)$ es la distancia euclidiana entre dos puntos así:

$$
d(X, Y)=\left[\sum_{j=1}^{J}\left(X_{j}-y_{j}\right)^{2}\right]^{1 / 2}
$$

En esta, $X=\left(x_{1}, x_{2}, \ldots . x_{J}\right), Y=\left(y_{1}, y_{2}, \ldots . y_{J}\right)$, vectores de orden $\mathrm{J}$, en este caso 4 , referente a los grados de exigencia requeridos.

«La medida $\mathrm{D}_{\mathrm{A}}^{\mathrm{B}}$ es la distancia correspondiente a cada categoría, obtenida mediante la suma de las distancias individuales de los diferentes elementos identificados en cada una de ellas. Así, $\mathrm{H}$ representa el número de ítems que componen cada categoría y $\mathrm{k}$ son los diferentes ítems o elementos contables» (Fuertes, 2006, p. 12).

Por ejemplo, en el IPSAS 16 de propiedades de inversión, en lo que respecta al tratamiento contable de la medición posterior, las entidades pueden optar por el modelo del valor razonable o el costo. Es decir, tendríamos un vector $(0,0,1,0)$, mientras la norma local exige el registro de esta información únicamente al costo histórico, o sea, un vector $(1,0,0,0)$. En ese sentido, tenemos una diferencia en valoración. Una vez determinadas las distancias euclidianas por vector, se agregan por cada estándar y así se obtienen los siguientes datos.

\section{Análisis de los resultados}

En la tabla 4, se muestran los diferentes tópicos analizados para las IPSAS y su equivalencia colombiana para entidades de gobierno, señalando la distribución del número total de conceptos y tratamientos contables identificados de acuerdo con el grado de exigencia de los mismos (obligatorio, recomendado, permitido y prohibido). Esta información se presenta ordenada en función del resultado obtenido en la medición de la distancia euclidiana, desde las que presentan la menor a la mayor diferencia.

El único tema en el que no se presentaron distancias fue en el de costos por préstamos. Hay diferencias leves, de apenas 1 punto o 1,4, en los tópicos de ingresos 
de transacciones con contraprestación, deterioro del valor de activos no generadores de efectivo, efecto de las variaciones en las tasas de cambio de la moneda extranjera y hechos ocurridos después de la fecha de presentación. Vale la pena mencionar también, con dos puntos de distancia, los acuerdos conjuntos y las provisiones, pasivos contingentes y activos contingentes, en los que parte de la discrepancia se sustenta en que la regulación local de entidades de gobierno conserva la clasificación de estos elementos en posibles, probables y remotos, distinción que no contienen las IPSAS.

Por el contrario, se presentan diferencias significativas, de más de cinco puntos de distancia, en los temas de reconocimiento y medición de instrumentos financieros, activos intangibles y presentación de estados financieros. En este sentido, para puntualizar de una forma más concreta la naturaleza de estas divergencias, en las tablas 5 y 6 , se ordenan los conceptos y principios en función de la clasificación entre aspectos de información y valoración, respectivamente.

En términos de las diferencias por conceptos y tratamientos contables de información, las más relevantes se pueden agrupar en dos áreas de divergencia:

a) El reconocimiento y la revelación de beneficios a empleados: La armonización contable internacional de temas como los beneficios post empleo es tan compleja como fundamental en el contexto de la sostenibilidad de las finanzas públicas (Biondi y Boisseau-Sierra, 2016). El carácter global de las IPSAS les exige tener un marco de principios amplio y flexible al que se puedan adaptar con facilidad una gran cantidad de diversas instituciones legales, y prácticas de control de las obligaciones de corto y largo plazo de las entidades de gobierno para con sus empleados.

En las IPSAS, se establecen lineamientos minuciosos sobre aspectos como los planes de beneficios definidos, planes multipatronales y gubernamentales, permisos retribuidos de corto plazo y participación en las ganancias, que no son corrientes en el caso local. En este sentido, quizá la estrategia normativa, más que atender directamente al reconocimiento y revelación de las particularidades reglamentarias locales en las normas, ha debido adoptar el marco internacional (para ampliar el referente de análisis) y, sobre el mismo, sí profundizar por medio de guías de aplicación intensas en ilustraciones y ejemplos que desarrollen las mencionadas particularidades a fin de facilitar su difusión y comprensión en el entorno estatal.

b) La presentación, revelación y consolidación de estados financieros: Se puede inferir que la reglamentación local, en general, es menos exigente en términos del número de revelaciones en los estados financieros. Esto puede producir un modelo de regulación menos costoso para las entidades de gobierno, en la medida en que deben procesar y divulgar menos información, pero tener como contrapartida una disminución de la relevancia y utilidad de la misma para la toma de decisiones económicas. Este es un tema para investigar con mucho más detalle, especialmente, desde una evaluación de la armonización material y del examen de la relevancia de la información contable pública en Colombia.

Vale decir, también, que las IPSAS contienen mucho más detalle y orientación que la norma local en tópicos como la identificación y revelación de segmentos, particularmente, estructuras de presentación no apropiadas, segmentos múltiples y distribución de diferentes elementos (activos conjuntos, por ejemplo) entre diferentes áreas. Igualmente, sucede con el citado caso de la consolidación de estados financieros, con conceptos como aplicación en empresas públicas, presentación de las participaciones no controladas, pérdida de control y entidades de inversión. 
Tabla 4. Conceptos y tratamientos contables clasificados de acuerdo con el grado de exigencia y ordenados en función de las distancias euclidianas entre las IPSAS y la normativa contable colombiana de entidades de gobierno (2015)

\begin{tabular}{|c|c|c|c|c|c|c|c|c|c|c|c|}
\hline \multirow[b]{2}{*}{$\begin{array}{l}\text { No. } \\
\text { IPSAS }\end{array}$} & \multicolumn{5}{|c|}{ IPSAS } & \multicolumn{5}{|c|}{ Norma colombiana } & \multirow[b]{2}{*}{$\begin{array}{l}\text { Distancia } \\
\text { euclidiana }\end{array}$} \\
\hline & $\begin{array}{l}\text { \# de conceptos } \\
\text { y tratamien- } \\
\text { tos contables } \\
\text { regulados }\end{array}$ & $\begin{array}{l}\text { Obli- } \\
\text { gatorio }\end{array}$ & $\begin{array}{c}\text { Reco- } \\
\text { mendado }\end{array}$ & $\begin{array}{l}\text { Permi- } \\
\text { tido }\end{array}$ & $\begin{array}{c}\text { Prohi- } \\
\text { bido }\end{array}$ & $\begin{array}{l}\text { \# de conceptos } \\
\text { y tratamien- } \\
\text { tos contables } \\
\text { regulados }\end{array}$ & $\begin{array}{l}\text { Obli- } \\
\text { gatorio }\end{array}$ & $\begin{array}{c}\text { Reco- } \\
\text { mendado }\end{array}$ & $\begin{array}{l}\text { Permi- } \\
\text { tido }\end{array}$ & $\begin{array}{l}\text { Prohi- } \\
\text { bido }\end{array}$ & \\
\hline 5 & 10 & 10 & 0 & 0 & 0 & 10 & 10 & 0 & 0 & 0 & 0 \\
\hline 9 & 12 & 11 & 0 & 1 & 0 & 11 & 11 & 0 & 0 & 0 & 1 \\
\hline 21 & 12 & 11 & 0 & 1 & 0 & 11 & 11 & 0 & 0 & 0 & 1 \\
\hline 4 & 8 & 7 & 0 & 1 & 0 & 8 & 8 & 0 & 0 & 0 & 1,414213562 \\
\hline 14 & 6 & 5 & 0 & 0 & 1 & 4 & 4 & 0 & 0 & 0 & 1,414213562 \\
\hline 19 & 21 & 16 & 0 & 0 & 5 & 19 & 15 & 0 & 0 & 4 & 2 \\
\hline 37 & 13 & 13 & 0 & 0 & 0 & 11 & 11 & 0 & 0 & 0 & 2 \\
\hline 23 & 18 & 17 & 0 & 1 & 0 & 15 & 15 & 0 & 0 & 0 & 2,236067977 \\
\hline 28 & 12 & 11 & 0 & 0 & 1 & 9 & 9 & 0 & 0 & 0 & 2,236067977 \\
\hline 32 & 17 & 16 & 0 & 1 & 0 & 14 & 14 & 0 & 0 & 0 & 2,236067977 \\
\hline 3 & 16 & 14 & 0 & 2 & 0 & 16 & 16 & 0 & 0 & 0 & 2,828427125 \\
\hline 26 & 31 & 29 & 0 & 2 & 0 & 27 & 27 & 0 & 0 & 0 & 2,828427125 \\
\hline 11 & 9 & 9 & 0 & 0 & 0 & 6 & 6 & 0 & 0 & 0 & 3 \\
\hline 12 & 13 & 10 & 0 & 3 & 0 & 9 & 9 & 0 & 0 & 0 & 3,16227766 \\
\hline 17 & 17 & 14 & 0 & 3 & 0 & 15 & 15 & 0 & 0 & 0 & 3,16227766 \\
\hline 27 & 10 & 9 & 0 & 1 & 0 & 6 & 6 & 0 & 0 & 0 & 3,16227766 \\
\hline 2 & 17 & 12 & 2 & 3 & 0 & 12 & 12 & 0 & 0 & 0 & 3,605551275 \\
\hline 36 & 14 & 11 & 0 & 3 & 0 & 9 & 9 & 0 & 0 & 0 & 3,605551275 \\
\hline 18 & 12 & 8 & 1 & 2 & 1 & 5 & 5 & 0 & 0 & 0 & 3,872983346 \\
\hline 13 & 23 & 21 & 0 & 1 & 1 & 18 & 17 & 0 & 1 & 0 & 4,123105626 \\
\hline 16 & 13 & 9 & 0 & 4 & 0 & 8 & 8 & 0 & 0 & 0 & 4,123105626 \\
\hline 25 & 32 & 28 & 0 & 4 & 0 & 27 & 26 & 0 & 0 & 1 & 4,582575695 \\
\hline 30 & 11 & 11 & 0 & 0 & 0 & 6 & 6 & 0 & 0 & 0 & 5 \\
\hline 35 & 14 & 14 & 0 & 0 & 0 & 9 & 9 & 0 & 0 & 0 & 5 \\
\hline 31 & 34 & 26 & 0 & 4 & 4 & 25 & 22 & 0 & 0 & 3 & 5,744562647 \\
\hline 1 & 47 & 36 & 2 & 8 & 1 & 33 & 32 & 0 & 1 & 0 & 8,366600265 \\
\hline 29 & 40 & 35 & 0 & 5 & 0 & 27 & 27 & 0 & 0 & 0 & 9,433981132 \\
\hline $\begin{array}{c}\text { TOTAL } \\
\%\end{array}$ & 482 & $\begin{array}{c}412 \\
86 \%\end{array}$ & $\begin{array}{c}5 \\
1 \%\end{array}$ & $\begin{array}{c}50 \\
10 \%\end{array}$ & $\begin{array}{r}15 \\
3 \%\end{array}$ & 370 & $\begin{array}{l}360 \\
97 \%\end{array}$ & $\begin{array}{c}0 \\
0 \%\end{array}$ & $\begin{array}{c}2 \\
1 \%\end{array}$ & $\begin{array}{c}8 \\
2 \%\end{array}$ & \\
\hline
\end{tabular}


Tabla 5. Conceptos y tratamientos contables de Información clasificados de acuerdo con el grado de exigencia y ordenados en función de las distancias euclidianas entre las IPSAS y la normativa contable colombiana de entidades de gobierno (2015)

\begin{tabular}{|c|c|c|c|c|c|c|c|c|c|c|c|}
\hline \multirow[b]{2}{*}{$\begin{array}{l}\text { No. } \\
\text { IPSAS }\end{array}$} & \multicolumn{5}{|c|}{ IPSAS } & \multicolumn{5}{|c|}{ Norma colombiana } & \multirow[b]{2}{*}{$\begin{array}{l}\text { Distancia } \\
\text { euclidiana }\end{array}$} \\
\hline & $\begin{array}{c}\text { \# de conceptos } \\
\text { y tratamien- } \\
\text { tos contables } \\
\text { regulados }\end{array}$ & $\begin{array}{c}\text { Obli- } \\
\text { gatorio }\end{array}$ & $\begin{array}{c}\text { Reco- } \\
\text { mendado }\end{array}$ & $\begin{array}{l}\text { Permi- } \\
\text { tido }\end{array}$ & $\begin{array}{l}\text { Prohi- } \\
\text { bido }\end{array}$ & $\begin{array}{l}\text { \# de conceptos } \\
\text { y tratamien- } \\
\text { tos contables } \\
\text { regulados }\end{array}$ & $\begin{array}{c}\text { Obli- } \\
\text { gatorio }\end{array}$ & $\begin{array}{c}\text { Reco- } \\
\text { mendado }\end{array}$ & $\begin{array}{l}\text { Permi- } \\
\text { tido }\end{array}$ & $\begin{array}{l}\text { Prohi- } \\
\text { bido }\end{array}$ & \\
\hline 5 & 8 & 8 & 0 & 0 & 0 & 8 & 8 & 0 & 0 & 0 & 0 \\
\hline 9 & 10 & 10 & 0 & 0 & 0 & 10 & 10 & 0 & 0 & 0 & 0 \\
\hline 21 & 9 & 9 & 0 & 0 & 0 & 9 & 9 & 0 & 0 & 0 & 0 \\
\hline 12 & 8 & 7 & 0 & 1 & 0 & 7 & 7 & 0 & 0 & 0 & 1 \\
\hline 17 & 8 & 7 & 0 & 1 & 0 & 7 & 7 & 0 & 0 & 0 & 1 \\
\hline 19 & 16 & 10 & 0 & 0 & 6 & 15 & 9 & 0 & 0 & 6 & 1 \\
\hline 23 & 12 & 12 & 0 & 0 & 0 & 11 & 11 & 0 & 0 & 0 & 1 \\
\hline 27 & 5 & 5 & 0 & 0 & 0 & 4 & 4 & 0 & 0 & 0 & 1 \\
\hline 4 & 7 & 6 & 0 & 1 & 0 & 7 & 7 & 0 & 0 & 0 & 1,414213562 \\
\hline 13 & 18 & 17 & 0 & 0 & 1 & 16 & 16 & 0 & 0 & 0 & 1,414213562 \\
\hline 14 & 6 & 5 & 0 & 0 & 1 & 4 & 4 & 0 & 0 & 0 & 1,414213562 \\
\hline 16 & 6 & 5 & 0 & 1 & 0 & 4 & 4 & 0 & 0 & 0 & 1,414213562 \\
\hline 31 & 19 & 15 & 0 & 1 & 3 & 16 & 14 & 0 & 0 & 2 & 1,732050808 \\
\hline 26 & 21 & 21 & 0 & 0 & 0 & 19 & 19 & 0 & 0 & 0 & 2 \\
\hline 32 & 15 & 15 & 0 & 0 & 0 & 13 & 13 & 0 & 0 & 0 & 2 \\
\hline 37 & 13 & 13 & 0 & 0 & 0 & 11 & 11 & 0 & 0 & 0 & 2 \\
\hline 28 & 12 & 11 & 0 & 0 & 1 & 9 & 9 & 0 & 0 & 0 & 2,236067977 \\
\hline 3 & 16 & 14 & 0 & 2 & 0 & 16 & 16 & 0 & 0 & 0 & 2,828427125 \\
\hline 36 & 13 & 11 & 0 & 2 & 0 & 9 & 9 & 0 & 0 & 0 & 2,828427125 \\
\hline 11 & 7 & 7 & 0 & 0 & 0 & 4 & 4 & 0 & 0 & 0 & 3 \\
\hline 29 & 21 & 21 & 0 & 0 & 0 & 18 & 18 & 0 & 0 & 0 & 3 \\
\hline 2 & 17 & 12 & 2 & 3 & 0 & 12 & 12 & 0 & 0 & 0 & 3,605551275 \\
\hline 18 & 12 & 8 & 1 & 2 & 1 & 5 & 5 & 0 & 0 & 0 & 3,872983346 \\
\hline 25 & 19 & 18 & 0 & 1 & 0 & 14 & 14 & 0 & 0 & 0 & 4,123105626 \\
\hline 30 & 11 & 11 & 0 & 0 & 0 & 6 & 6 & 0 & 0 & 0 & 5 \\
\hline 35 & 14 & 14 & 0 & 0 & 0 & 9 & 9 & 0 & 0 & 0 & 5 \\
\hline 1 & 47 & 36 & 2 & 8 & 1 & 33 & 32 & 0 & 1 & 0 & 8,366600265 \\
\hline $\begin{array}{c}\text { TOTAL } \\
\%\end{array}$ & 370 & $\begin{array}{l}328 \\
89 \%\end{array}$ & $\begin{array}{c}5 \\
1 \%\end{array}$ & $\begin{array}{l}23 \\
6 \%\end{array}$ & $\begin{array}{r}14 \\
4 \%\end{array}$ & 296 & $\begin{array}{l}287 \\
97 \%\end{array}$ & $\begin{array}{c}0 \\
0 \%\end{array}$ & $\begin{array}{c}1 \\
0 \%\end{array}$ & $\begin{array}{c}8 \\
3 \%\end{array}$ & \\
\hline
\end{tabular}


Tabla 6. Conceptos y tratamientos contables de Valoración clasificados de acuerdo con el grado de exigencia y ordenados en función de las distancias euclidianas entre las IPSAS y la normativa contable colombiana de entidades de gobierno (2015)

\begin{tabular}{|c|c|c|c|c|c|c|c|c|c|c|c|}
\hline \multirow[b]{2}{*}{$\begin{array}{l}\text { No. } \\
\text { IPSAS }\end{array}$} & \multicolumn{5}{|c|}{ IPSAS } & \multicolumn{5}{|c|}{ Norma colombiana } & \multirow[b]{2}{*}{$\begin{array}{l}\text { Distancia } \\
\text { euclidiana }\end{array}$} \\
\hline & $\begin{array}{l}\text { \# de conceptos } \\
\text { y tratamien- } \\
\text { tos contables } \\
\text { regulados }\end{array}$ & $\begin{array}{l}\text { Obli- } \\
\text { gatorio }\end{array}$ & $\begin{array}{c}\text { Reco- } \\
\text { mendado }\end{array}$ & $\begin{array}{c}\text { Permi- } \\
\text { tido }\end{array}$ & $\begin{array}{l}\text { Prohi- } \\
\text { bido }\end{array}$ & $\begin{array}{l}\text { \# de conceptos } \\
\text { y tratamien- } \\
\text { tos contables } \\
\text { regulados }\end{array}$ & $\begin{array}{c}\text { Obli- } \\
\text { gatorio }\end{array}$ & $\begin{array}{c}\text { Reco- } \\
\text { mendado }\end{array}$ & $\begin{array}{l}\text { Permi- } \\
\text { tido }\end{array}$ & $\begin{array}{c}\text { Prohi- } \\
\text { bido }\end{array}$ & \\
\hline 4 & 1 & 1 & 0 & 0 & 0 & 1 & 1 & 0 & 0 & 0 & 0 \\
\hline 5 & 2 & 2 & 0 & 0 & 0 & 2 & 2 & 0 & 0 & 0 & 0 \\
\hline 11 & 2 & 2 & 0 & 0 & 0 & 2 & 2 & 0 & 0 & 0 & 0 \\
\hline 9 & 2 & 1 & 0 & 1 & 0 & 1 & 1 & 0 & 0 & 0 & 1 \\
\hline 19 & 5 & 5 & 0 & 0 & 0 & 4 & 4 & 0 & 0 & 0 & 1 \\
\hline 21 & 3 & 2 & 0 & 1 & 0 & 2 & 2 & 0 & 0 & 0 & 1 \\
\hline 32 & 2 & 1 & 0 & 1 & 0 & 1 & 1 & 0 & 0 & 0 & 1 \\
\hline 36 & 1 & 0 & 0 & 1 & 0 & 0 & 0 & 0 & 0 & 0 & 1 \\
\hline 23 & 6 & 5 & 0 & 1 & 0 & 4 & 4 & 0 & 0 & 0 & 1,414213562 \\
\hline 26 & 10 & 8 & 0 & 2 & 0 & 8 & 8 & 0 & 0 & 0 & 2 \\
\hline 12 & 5 & 3 & 0 & 2 & 0 & 2 & 2 & 0 & 0 & 0 & 2,236067977 \\
\hline 17 & 9 & 7 & 0 & 2 & 0 & 8 & 8 & 0 & 0 & 0 & 2,236067977 \\
\hline 27 & 5 & 4 & 0 & 1 & 0 & 2 & 2 & 0 & 0 & 0 & 2,236067977 \\
\hline 13 & 5 & 4 & 0 & 1 & 0 & 2 & 1 & 0 & 1 & 0 & 3 \\
\hline 16 & 7 & 4 & 0 & 3 & 0 & 4 & 4 & 0 & 0 & 0 & 3 \\
\hline 25 & 13 & 10 & 0 & 3 & 0 & 13 & 12 & 0 & 0 & 1 & 3,741657387 \\
\hline 31 & 15 & 11 & 0 & 3 & 1 & 9 & 8 & 0 & 0 & 1 & 4,242640687 \\
\hline 29 & 19 & 14 & 0 & 5 & 0 & 9 & 9 & 0 & 0 & 0 & 7,071067812 \\
\hline $\begin{array}{c}\text { TOTAL } \\
\%\end{array}$ & 112 & $\begin{array}{c}84 \\
75 \%\end{array}$ & $\begin{array}{c}0 \\
0 \%\end{array}$ & $\begin{array}{c}27 \\
24 \%\end{array}$ & $\begin{array}{c}1 \\
1 \%\end{array}$ & 74 & $\begin{array}{c}71 \\
96 \%\end{array}$ & $\begin{array}{c}0 \\
0 \%\end{array}$ & $\begin{array}{c}1 \\
1 \%\end{array}$ & $\begin{array}{c}2 \\
3 \%\end{array}$ & \\
\hline
\end{tabular}

La consolidación de estados financieros es un aspecto novedoso para las entidades de gobierno colombianas, que se dificultará con el establecimiento de políticas contables uniformes en el marco de los tres diferentes modelos de contabilidad del sector público descritos en el primer apartado. Esto supone, especialmente, en las entidades de nivel territorial, una disyuntiva entre el aumento de los costos del proceso de agregación y la formulación de los reportes consolidados y el objetivo de ofrecer una representación fiel de la responsabilidad política y los resultados de un programa de gobierno desarrollado por una autoridad ejecutiva determinada.

En cuanto a la distancia de los marcos normativos estudiados, en el campo de la valoración, se encuentra que la principal diferencia radica en que la norma colombiana no permite el uso integral del valor razonable y restringe su aplicación a los valores de mercado. 
Esta divergencia se hace más notable en elementos en que las IPSAS priorizan su aplicación, como la medición de los activos biológicos; los arrendamientos; las propiedades de inversión; los activos intangibles; $y$, primordialmente, los instrumentos financieros, cuyo reconocimiento, medición y revelación constituyen otro de los puntos de significativo distanciamiento.

El mismo desarrollo del tema en las IPSAS aún es insuficiente; no hay un parámetro de orientación concreto sobre esta base de medición (CGN, 2015a). No obstante, la escasa literatura al respecto muestra que el uso del valor razonable aumenta la pertinencia de la información financiera, en tanto que facilita evaluar la solvencia de las entidades estatales y su capacidad de generar recursos a través de la venta de activos y la liquidación de pasivos, especialmente, de tipo financiero (Navarro y Rodríguez, 2004, 2011). También, puede llegar a ser más oportuno a la hora de evaluar los costos y los riesgos asociados a los apoyos de crédito y financiación estatal que adelantan los gobiernos en el marco de su política fiscal (Lucas, 2014).

Señalan, de igual modo, que, en el caso de los activos no financieros, en muchas ocasiones, el valor razonable tiene un mayor grado de relevancia informativa frente al costo. En contrapeso, se reconoce que su cálculo puede llegar a ser más oneroso fiscalmente y, también, que la fiabilidad de las mediciones contables puede disminuir considerablemente, lo cual afecta la transparencia y la rendición de cuentas de las entidades de gobierno (Rodríguez y Navarro, 2012; Gardini y Grossi, 2014).

La aplicación del valor razonable en las finanzas públicas es un área que requiere una mayor cantidad de estudio, análisis empírico, y regulación ${ }^{3}$ para definir y aprovechar sus potenciales beneficios en la elaboración de la información contable pública al menor costo de determinación.

\section{Conclusiones y perspectivas de investigación futuras}

Los resultados obtenidos a partir de la medición de las distancias euclidianas en la comparación del marco normativo contable colombiano para las entidades de gobierno y las IPSAS permiten concluir que hay considerables diferencias técnicas entre los dos esquemas en contravía de la convergencia. Esto podría disminuir los beneficios potenciales de la armonización formal como una mayor comparabilidad, relevancia y calidad de la información financiera gubernamental colombiana.

También, se observa que tanto las normas colombianas como las IPSAS guardan una relación de 80\%-20\% aproximadamente entre lineamientos contables de información y valoración respectivamente. La regulación local contiene menos principios y limita la posibilidad de aplicar tratamientos alternativos, debido a que establece una alta proporción de requerimientos de carácter obligatorio o prohibido. Esto contribuiría a lograr más uniformidad en la elaboración y en el reporte de la información financiera. El análisis de este aspecto puede complementarse con la investigación de la armonización material, a partir de los índices de Herfindahl o comparabilidad, por ejemplo, a fin de entender la implementación práctica de la normatividad en términos del establecimiento, y el desarrollo de las políticas y los procesos contables específicos de cada entidad de gobierno.

3 En este sentido, el Governmental Accounting Standards Board (GASB) ha dado un importante paso el emisor de la contabilidad pública en los Estados Unidos al emitir su estándar número 72 sobre medición y aplicación del valor razonable (GASB, 2015). 
El sentido positivo que tiene la limitación del empleo de tratamientos contables alternativos en las normas colombianas se ve restringido por la complejidad que toma el sistema de regulación local con la emisión de dos cuerpos normativos adicionales al de las entidades de gobierno, dirigidos a las empresas públicas que cotizan en los mercados de valores y las que no, que usan principios más cercanos a las IFRS. Esta situación se podrá apreciar con más intensidad en el aumento de los costos del proceso de consolidación de los estados financieros, puesto que las entidades de gobierno tendrán que homologar y dar uniformidad a las cifras de tres modelos diferentes.

Una estrategia alternativa hubiera sido adoptar integralmente las IPSAS para las entidades de gobierno y las empresas públicas no cotizantes en mercados de valores, y que sobre las mismas la CGN definiera restricciones a la aplicación sobre principios o tratamientos contables que no se consideren pertinentes para el entorno nacional o no estén desarrollados en las IPSAS. Este es el sentido inicial de la propuesta de las European Public Sector Accounting Standards (EPSAS) (European Commission, 2013). Esto se puede evidenciar, por ejemplo, en la necesidad de parámetros de reconocimiento, medición y revelación más puntuales sobre los bienes históricos, culturales y de uso público (heritage assets) (Aversano y Christiaens, 2014).

Con esta fórmula, es más probable que aumente la armonización formal, sin dejarse de desarrollar temas particulares a nivel local. De igual modo, se reducen los riesgos de que la norma colombiana pierda actualización, o que áreas de trabajo emergentes se evalúen más tardíamente por divergencias entre las agendas y los objetivos del emisor local y el internacional. Además, sería más sencillo para usuarios de la información contable gubernamental extranjeros, como fondos de inversión, calificadoras de riesgo, prestamistas multilaterales, donantes y analistas internacionales, entender la información financiera derivada de dicha reglamentación. Esto es más evidente en aspectos que muestran puntajes de diferencia más significativos, como el reconocimiento y la medición de los instrumentos financieros (un término que no contiene la norma colombiana), y la presentación y la revelación de estados financieros.

En este sentido, hay también bastante potencial de análisis en tópicos relativamente novedosos, como la consolidación de estados financieros y la información segmentada, que también mostraron una alta distancia euclidiana. De igual modo, se encuentra potencial en otros tópicos que, por diferentes razones, no se consideraron adecuados en la estrategia de convergencia, como los reportes de presupuestos y las revelaciones sobre partes relacionadas y otras entidades.

Vale la pena resaltar además que, desde el punto de vista de los elementos informativos, la divergencia se encontró principalmente en el menor número de requerimientos por parte de la normatividad colombiana de entidades de gobierno, de revelaciones de información cualitativa de distinto orden. Mientras, en el campo de la valoración, la distancia se explica en un alto porcentaje, porque en el modelo local no se adoptó de manera integral el criterio de valor razonable; solo se permite en algunas ocasiones la utilización de valores de mercado. Esto, hipotéticamente (esta es otra perspectiva de investigación), podría afectar la relevancia de la información financiera y su capacidad para reflejar riesgos, especialmente, de rubros como las propiedades de inversión, los intangibles, los instrumentos financieros, los activos biológicos, entre otros.

Finalmente, todos estos aspectos indican que hay bastantes temáticas para investigar, $\mathrm{y}$, especialmente, 
oportunidades para avanzar en la modernización y la transparencia de las cuentas y los reportes gubernamentales en Colombia, y más extensamente, en América Latina, en favor de los ciudadanos y la democracia regional.

\section{Referencias}

Aggestam-Pontoppidan, Caroline e Isabelle Andernack (2016). Interpretation an application of IPSAS. Padstow: John Wiley \& Sons.

Archer, Simon, Pascale Delvaille y Stuart McLeay (1995). The measurement of harmonization and the comparability of financial statement items: within-country and between-country effects. Accounting and Business Research, 25(98), 67-80. https://doi.org/10.1080/000 14788.1995 .9729930

Archer, Simon, Pascale Delvaille y Stuart McLeay (1996). A statistical model of international accounting harmonization. Abacus, 32(1), 1-29.

Aversano, Natalia y Johan Christiaens (2014). Governmental financial reporting of heritage assets from a user need perspective. Financial Accountability \& Management, 30(2), 150-174. https://doi.org/10.1111/ faam. 12032

Biondi, Yuri y Marion Boisseau-Sierra (2016). Accounting for pension obligations in the European Union: A case study for EPSAS and transnational budgetary supervision. 14th International Conference on Pension, Insurance and Saving. University of Paris Dauphine and University of Berkeley. París, 27 de mayo.

Bohórquez, Pedro (2016). Contabilidad pública para un Estado moderno. Revista Internacional Legis de Contabilidad \& Auditoría, 23, 9-12.

Brusca, Isabel, Mauricio Gómez y Vicente Montesinos (2016). Public financial management reforms: The role of IPSAS in Latin-America. Public Administration and Development, 36(1), 51-64. https://doi. org/10.1002/pad. 1747
Caba, Carmén y Elisa Caba (2005). La armonización de la información financiera pública en los países de la CAN. Revista Internacional Legis de Contabilidad \& Auditoría, 23, 141-179.

Caba, Carmén y Antonio López (2003). La difusión de información financiera gubernamental en los países del Mercosur: su armonización a través de la aplicación de las IPSAS de IFAC. Revista de Contabilidade \& Finanças, 14(33), 90-100. https://doi.org/10.1590/ s1519-70772003000300007

Cañibano, Leandro y Araceli Mora (2000). Evaluating the statistical significance of 'de facto' accounting harmonization: A study of European Global Players. European Accounting Review, 9(3), 349-370. https:// doi.org/10.1080/09638180020017113

Cavanagh, Joseph y Almudena Fernández (2015). Contabilidad pública y credibilidad fiscal. En Carlos Pimenta y Mario Pessoa (eds.). Gestión financiera pública en América Latina: La clave de la eficiencia y la transparencia. Nueva York: Banco Interamericano de Desarrollo / Fondo Monetario Internacional), 191-249.

Contaduría General de la Nación (CGN) (2013). Estrategia de convergencia de la regulación contable pública hacia Normas Internacionales de Información Financiera (NIIF) y Normas Internacionales de Contabilidad del Sector Público (NICSP). Bogotá: Imprenta Nacional de Colombia. Consulta: 27 de mayo de 2016. http://www. contaduria.gov.co/wps/wcm/connect/8b13e1fa-c7c94079-8f1d-9588d5d44f4a/Estrategia+de+convergenc $\mathrm{ia}+\mathrm{de}+\mathrm{la}+$ regulaci $\% \mathrm{C} 3 \% \mathrm{~B} 3 \mathrm{n}+$ contable $+\mathrm{p} \% \mathrm{C} 3 \% \mathrm{BAb}$ lica+hacia+NIIF+y+NICSP.pdf?MOD=AJPERES

Contaduría General de la Nación (CGN) (2015a). Cambios enlapolíticaderegulacióncontablepúblicayenladefinición del marco normativo de las entidades de Gobierno. Bogotá: CGN. Consulta: 27 de mayo de 2016. http://www. contaduria.gov.co/wps/wcm/connect/628930bca6b6-4b04-b3d0-e47682f769bc/Cambios+en+la+pol \%C3\%ADtica+\%2816-10-15\%29.pdf?MOD= AJPERES \&CONVERT_TO $=$ url $\&$ CACHEID $=628930 \mathrm{bc}-\mathrm{a} 6 \mathrm{~b} 6-4 \mathrm{~b} 04-\mathrm{b} 3 \mathrm{~d} 0-\mathrm{e} 47682 \mathrm{f} 769 \mathrm{bc}$

Contabilidad y Negocios (12) 24, 2017 / ISSN 1992-1896 
Contaduría General de la Nación (CGN) (2015b). Normas para el reconocimiento, medición, revelación y presentación de los hechos económicos de las entidades de Gobierno. Bogotá: Imprenta Nacional de Colombia. Consulta: 27 de mayo de 2016. http://www.contaduria.gov.co/ wps/wcm/connect/b9cdb1d6-922d-42d2-81faece7acbdf298/Normas+RMRP+\%28Oct+8-15\%29. pdf? MOD=AJPERES \&CACHEID = b9cdb $1 \mathrm{~d} 6-$ $922 \mathrm{~d}-42 \mathrm{~d} 2-81 \mathrm{fa}-$ ece 7 acbdf298

Emenyonu, Emmanuel y Sidney Gray (1992). EC Accounting harmonization: An empirical study of measurement practices in France, Germany and the UK. Accounting and Business Research, 23(89), 49-58. https://doi.org/10.1080/00014788.1992.9729860

European Commission (2013). Report from the Commission to the Council and the European Parliament. Towards implementing harmonized public-sector accounting standards in Member States. The suitability of IPSAS for Member States. Bruselas, 6 de marzo. Consulta: 27 de mayo de 2016. http://eur-lex.europa.eu/legal-content/EN/TXT/ $\mathrm{PDF} /$ ?uri=CELEX:52013DC0114\&from=EN

Fontes, Alexandra, Lúcia Rodrigues y Rusell Craig (2005). Measuring convergence of national accounting standards with International Financial Reporting Standards. Accounting Forum, 29, 415-436. https:// doi.org/10.1016/j.accfor.2005.05.001

Fuertes, Iluminada (2006). El modelo de contabilidad pública de internacional de la IFAC: Análisis de la armonización formal. Novena Jornada de Contabilidad Pública. Asociación Española de Profesores Universitarios de Contabilidad (Asepuc). Logroño, 23-24 de febrero.

Fuertes, Iluminada (2007). Un análisis del grado de comparabilidad de la información contable pública basado en la rigidez del marco regulador del IFAC. Presupuesto y Gasto Público, 47, 65-86.

García Benau, María (1995). Armonización de la información financiera en Europa. Madrid: Instituto de Contabilidad y Auditoría de Cuentas.
Gardini, Silvia y Giuseppe Grossi (2014). Voluntary adoption of the consolidated financial statement and fair value accounting by Italian local governments. Journal of Public Budgeting, Accounting \& Financial Management, 26(2), 313-344. https://doi.org/10.1108/ jpbafm-26-02-2014-b004

Garrido, Pascual, Ángel León y Ana Zorio (2002). Measurement of formal harmonization progress: The IASC experience. The International Journal of Accounting, 37, 1-26. https://doi.org/10.1016/s00207063(02)00144-9

Gómez, Mauricio y Vicente Montesinos (2012). Las innovaciones en contabilidad gubernamental en Latinoamérica: El caso de Colombia. Innovar, 22(45), 17-35.

Gómez, Oda, Aminta De La Hoz y Betty De la Hoz (2011). Armonización de las NIC/NIIF en las prácticas contables de entes emisores no financieros que cotizan en la Bolsa de Valores Caracas, Venezuela. Contaduría y Administración, 233, 149-175.

González, Patricia (2006). Estudio empírico para medir aspectos de armonización entre las prácticas y normas contables utilizadas por las empresas argentinas, brasileñas y colombianas. Cuadernos de Administración, 34, 177-196. https://doi.org/10.25100/cdea.v21i34.220

Governmental Accounting Standards Board (GASB) (2015). Statement No. 72. Fair value measurement and application. Norwalk: GASB.

Herrmann, Don y Wayme Thomas (1995). Harmonization of practices in the European Community. Accounting and Business Research, 25(100), 253-265.

International Public-Sector Accounting Standards Board (IPSASB) (2015). Handbook of International Public-Sector Accounting Pronouncements. Nueva York: International Federation of Accountants (IFAC).

Jarne, Ignacio (1997). Clasificación y evolución internacional de los sistemas contables. Madrid: Asociación Española de Contabilidad y Administración de Empresas. 
Krisement, Vera (1997). An approach for measuring he degree of comparability of financial accounting. European Accounting Review, 6(3), 465-485. https:// doi.org/10.1080/713764728

Lucas, Deborah (2014). Evaluating the cost of government credit support: The OECD context. Economic Policy, 29(79), 553-597. https://doi. org/10.1111/1468-0327.12034

McLeay, Stuart, David Neal y Tony Tollington (1999). International standardization and harmonization: $\mathrm{A}$ new measurement technique. Journal of International Financial Management and Accounting, 10(1), 42-70.

Morris, Richard y R. Parker (1998). International harmony measures of accounting policy: Comparative statistical properties. Accounting and Business Research, 29(1), 73-86. https://doi.org/10.1080/00014788.1998.972 9567

Navarro, Andrés y Manuel Rodríguez (2004). Análisis de la utilidad del fair value para la valoración de activos de las administraciones públicas españolas. Revista de Contabilidad, 7(13), 245-273.

Navarro, Andrés y Manuel Rodríguez (2011). Utilidad del modelo de valoración de las IPSAS para la rendición de cuentas de los gobiernos: La perspectiva de la OCEX. Revista Española de Financiación y de Contabilidad,
40(149), 125-162. https://doi.org/10.1080/0210241 2.2011 .10779700

Pereira, Bento y Ricardo Correa (2013). International experiences with accrual budgeting in the public sector. Revista de Contabilidade \& Finanças, 24(62), 103-112.

Rahman, Asheq, Héctor Perera y Siva Ganeshanandam (1996). Measurement of formal harmonization in accounting: An exploratory study. Accounting and Business Research, 26(4), 325-339. https://doi.org/10.10 80/00014788.1996.9729522

Rodríguez, Manuel y Andrés Navarro (2012). The role of fair value accounting in promoting government accountability. Abacus, 48(3), 348-386. https://doi. org/10.1111/j.1467-6281.2011.00352.x

Tay, J. y R. Parker (1990). Measuring international harmonization and standardization. Abacus, 26(1), 71-88.

Van der Tas, Leo (1988). Measuring harmonization of financial reporting practice and standardization. Accounting and Business Research, 18(70), 157-169.

Recibido: 08/02/2017 Aceptado: 18/10/2017 carlosricob@usantotomas.edu.co michaeldiazj@usantotomas.edu.co 